\title{
EDUCAÇÃO AMBIENTAL NA EDUCAÇÃO PROFISSIONAL E TECNOLÓGICA: ENSINO A PARTIR DE JOGOS EDUCATIVOS DE DESCARTE DE LIXO ELETRÔNICO
}

Ana Sara Castaman ${ }^{1}$ Lis Ângela De Bortoli

Resumo: A tecnologia aliada à obsolescência programada e ao consumismo exacerbado contribuem significativamente para a intensificação de resíduos eletroeletrônicos. Com base nessa problemática, foram elaborados jogos educativos de descarte de lixo eletroeletrônico, os quais foram aplicados na unidade curricular de Educação Ambiental a estudantes da Educação Profissional e Tecnológica (EPT), do Instituto Federal de Educação, Ciência e Tecnologia do Rio Grande do Sul (IFRS) - Campus Sertão. Para tanto, este estudo de caso tem por objetivo relatar tal experiência de confecção e execução de jogos educativos no ensino da Educação Ambiental na EPT. Com base na avaliação realizada, a experiência foi positiva para o processo de ensino e aprendizagem, possibilitando unir teoria e prática, de forma lúdica.

Palavras-chave: Jogos Educativos; Ensino; Lixo Eletrônico; Educação Ambiental.

${ }^{1}$ Instituto Federal de Educação, Ciência e Tecnologia do Rio Grande do Sul - Campus Sertão. E-mail: ana.castaman@sertao.ifrs.edu.br, Link para o Lattes: http://lattes.cnpq.br/0260327866661542

${ }^{2}$ Instituto Federal de Educação, Ciência e Tecnologia do Rio Grande do Sul - Campus Sertão.

E-mail: lis.debortoli@sertao.ifrs.edu.br, Link para o Lattes: http://lattes.cnpq.br/2981004695590778

Revbea, São Paulo, V. 15, № 5: 76-88, 2020. 
Abstract: Technology coupled with programmed obsolescence and exacerbated consumerism contribute significantly to the intensification of eletroelectronic waste. Based on this problem, educational games for the disposal of eletroelectronic waste were developed, which were applied in the course of Environmental Education to students of Professional and Technological Education (EPT), of the Federal Institute of Education, Science and Technology of Rio Grande do Sul. (IFRS) - Campus Sertão. Therefore, this case study aims to report such experience of making and executing educational games in the teaching of environmental education in EFA. Based on the evaluation performed, the experience was positive for the teaching and learning process, making it possible to unite theory and practice in a playful way.

Keywords: Educational Games; Teaching; Electronic Waste; Environmental Education.

\section{Introdução}

A Educação Ambiental remete a processos por meio dos quais o sujeito e a coletividade "[...] constroem valores sociais, conhecimentos, habilidades, atitudes, competências voltadas para a conservação do meio ambiente, bem de uso comum do povo, essencial à sadia qualidade de vida e sua sustentabilidade" (BRASIL, 1999, art. $1^{\circ}$ ). A Conferência das Nações Unidas acerca do Meio Ambiente e Desenvolvimento, nomeada como Rio-92, apresenta três eixos de organização da Educação Ambiental, os quais foram amplamente discutidos na mesma: reorientação do ensino para o desenvolvimento sustentável, aumento da consciência pública e promoção do treinamento (ONU, 1992).

O Decreto $n^{\circ} \mathbf{4 . 2 8 1}$, de 25 de junho de 2002, que regulamenta a Lei $n$ 9.795, de 27 de abril de 1999 e institui a Política Nacional de Educação Ambiental, e dá outras providências, indica no art. 5a inclusão desse tema em todos os níveis e as modalidades de ensino. Ainda, recomenda como referência os Parâmetros e as Diretrizes Curriculares Nacionais, observando: "I - a integração da Educação Ambiental às disciplinas de modo transversal, contínuo e permanente; e II - a adequação dos programas já vigentes de formação continuada de educadores" (BRASIL, 2002, p. 01).

Assim, não é necessário ter uma unidade curricular específica sobre Educação Ambiental, mas "[...] implica no desenvolvimento de hábitos e atitudes sadias de conservação ambiental e respeito à natureza, a partir do cotidiano da vida, da escola e da sociedade" (BRASIL, 1996). No que concerne ao ensino na Educação Profissional e Tecnológica (EPT), mais especificamente, ao curso Técnico em Manutenção e Suporte em Informática, modalidade concomitância externa, do Instituto Federal de Educação, Ciência e Tecnologia do Rio Grande do Sul (IFRS) - Campus Sertão, a Educação Ambiental é abordada sob forma de unidade curricular, a constar na matriz no $5^{\circ}$ semestre. Tem como objetivo geral 
Proporcionar a busca uma ação holística na área ambiental, para sua aplicação na Educação Ambiental de forma: multi, inter, e transdisciplinar, contribuindo em programas diversos, em uma atividade integrada de reflexão constante, em relação a própria cientificidade de uma dada prática de pesquisa, e em relação aos resultados das diversas ciências, sem romper com a especificidade do olhar ecológico (IFRS, 2013, p. 43).

A docente responsável pela unidade curricular desde 2017, em parceira com o Projeto de Extensão "E-Lixo: ações de descarte, reutilização e Educação Ambiental" (IFRS, 2019), produziu jogos educativos pautados na reutilização de materiais de resíduos eletroeletrônicos para aplicar no referido componente curricular. Os jogos educativos "[...] com finalidades pedagógicas revelam a sua importância, pois promovem situações de ensino-aprendizagem e aumenta a construção do conhecimento"' (FIALHO, 2008, p.12999).

Cada vez mais têm sido empregados jogos didáticos para a mediação e a construção do conhecimento nos espaços escolares. Entende-se que estes colaboram para despertar emoções e conduzir os participantes a uma experiência que os incentive a enfrentar as dificuldades apresentadas (GOMES; FRIEDRICH, 2001). Ainda, tem por propósito otimizar o rendimento escolar dos estudantes, o processo de ensino-aprendizagem de conteúdos específicos, o desenvolvimento do raciocínio do aluno, a socialização, a motivação, a curiosidade e a criatividade (ZANON; GUERREIRO; OLIVEIRA, 2008).

Destarte, este estudo de caso, de abordagem qualitativa, tem por finalidade apresentar um relato de experiência acerca da construção e da aplicação de jogos educativos de descarte de lixo eletrônico no ensino da Educação Ambiental na EPT, no IFRS - Campus Sertão. Está dividido em 02 partes: a) trata dos conceitos e dos fundamentos acerca dos jogos educativos e das suas contribuições para o ensino; b) aborda a experiência de produção e de aplicação de jogos educativos de descarte de lixo eletroeletrônico na unidade curricular de Educação Ambiental no IFRS - Campus Sertão.

\section{Jogos educativos: contribuições para o processo de ensino}

Para mediação do processo de ensino e aprendizagem, geralmente, os docentes empregam estratégias de ensinagem (PIMENTA; ANASTASIOU, 2002) e/ou jogos educativos, de modo a permitir a construção do conhecimento, a participação, a reflexão e a criticidade do estudante. Taylor (1991) e Brougère (1998) destacam contribuições dos jogos para a educação: exploração do mundo segura e confortavelmente; reprodução de cenários, situações ou problemas concretos simplificada e didaticamente; vivência de problemas reais em contextos imaginários; exercício de habilidades e ações que podem ser exigidas em desafios reais; estímulo e exercício da participação ativa dos estudantes; criação de situações que mediam as relações 
interpessoais; compreensão e resolução de problemas reais; relaxamento e aumento da autoconfiança, entre outros.

Lara (2004), ressalta que os jogos educativos vêm ganhando espaço nas instituições de ensino, no intuito de inserir o lúdico em sala de aula. Reforça que grande parte dos docentes utiliza os mesmos para tornar as aulas mais prazerosas, estimular o processo de aprendizagem, bem como propiciar que o estudante enfrente situações de conflito relacionadas com o seu cotidiano.

Os jogos educativos constituem-se como uma ferramenta agradável e, ao mesmo tempo, que possibilita ao sujeito firmar "[...] oportunidades de encontrar soluções e interagir com outros usuários, permitindo então o processo de atividades colaborativas e ampliando as estratégias coletivas de uma maneira estimulante e lúdica" (ZORZAL et al., 2008, p. 02). Para Grübel e Bez (2006, p. 6), os jogos educativos:

[...] além de serem divertidos dando destaque ao lúdico, quando usados pedagogicamente, auxiliam os educandos na criação e familiarização de conhecimentos. [...] Utilizados de forma adequada [...] com certeza, acrescentam-se à educação como mais um agente transformador, enriquecendo as aulas de forma divertida e animada [...].

Oliveira, Costa e Moreira (2001, p. 81) marcam que os jogos educacionais têm como finalidade o entretenimento para o usuário, podendo influenciar também o seu desenvolvimento social, afetivo e cognitivo.

Podem apresentar situações que contenham simulações, tutoriais ou sistemas inteligentes, mas o que evidencia esse tipo de software é seu caráter de divertimento, de prazer. Uma situação de jogo oferece aos usuários intensa interatividade, permitindo ampliar as relações sociais no ambiente de ensino, cativando o interesse dos alunos em relação a temas muitas vezes difíceis de ser apresentados por outras abordagens. A essência do jogo educacional é a aprendizagem com prazer e a criatividade com diversão.

Silveira e Barone (1998), complementam que os jogos educativos podem ser realizados em sala de aula com inúmeros propósitos, sendo os mais básicos a construção da autoconfiança e da motivação. Para os autores, é uma estratégia eficaz que proporciona "[...] informações factuais e praticar habilidades, conferindo destreza e competência" (SILVEIRA; BARONE, 1998, p.2). 
Há muitos tipos e modelos de jogos pedagógicos, no entanto, independente destes é imprescindível que os mesmos sejam capazes de estimular e enriquecer a experimentação do estudante, a partir da interação e facilitar a construção do conhecimento. Nesta perspectiva, na seção que segue, explicita-se a experiência da construção e da aplicação de jogos educativos baseados em materiais de reciclagem, na unidade curricular de Educação Ambiental, no IFRS - Campus Sertão.

\section{E-Lixo: jogos educativos}

A unidade curricular de Educação Ambiental, totaliza 20h, consta no $5^{\circ}$ semestre do curso Técnico em Manutenção e Suporte em Informática, modalidade concomitância externa, do Instituto Federal de Educação, Ciência e Tecnologia do Rio Grande do Sul (IFRS) - Campus Sertão. Tem por finalidade introduzir os conceitos de meio ambiente e de Educação Ambiental, a partir de propostas de atividades práticas sobre os temas para que os estudantes possam vivenciá-las no campus, contribuindo para a sua formação como cidadãos (IFRS, 2013). Quanto à Educação Ambiental, Layrargues (1999), marca que é uma área que busca a sensibilização ou a conscientização e entendimento da complexa interação dos elementos ecológicos que se atrelam ao campo político, econômico, histórico e sociocultural. Reigota (1994, p. 2526), acrescenta que:

A escola é um local privilegiado para a realização da Educação Ambiental, desde que se dê oportunidade à criatividade. Embora a ecologia, como ciência, tenha uma importante contribuição a dar à Educação Ambiental, ela não está mais autorizada que a história, o português, a química, a geografia, a física, etc.

No que tange ao componente curricular supracitado, ressalta-se que, por ser teórico/prático integrado ao curso Técnico em Manutenção e Suporte em Informática, o foco em estudo está na questão do lixo eletroeletrônico e das suas implicações para o ser humano e para a natureza. Assim, para dar conta do fundamento da unidade curricular e do curso ao qual se inscreve, a docente responsável, produziu jogos educativos com descarte de lixo, em parceria com o Projeto de Extensão "E-Lixo: ações de descarte, reutilização e Educação Ambiental". O Projeto de Extensão tem por objetivo conscientizar a comunidade sobre o lixo eletroeletrônico produzido e a importância de um destino ambientalmente adequado para estes equipamentos. As atividades ocorrem a partir de oficinas, exposições, bate-papos e jogos educacionais, produzidos por meio de materiais arrecadados em mutirões de coleta (DE BORTOLI, 2019).

Assim, foram elaborados por oito (08) estudantes/bolsistas e a professora, nove (09) jogos educativos, baseados na Resolução CONAMA no 
275 (2019), que estabelece o código de cores para os diferentes tipos de resíduos, a ser adotado na identificação de coletores e de transportadores, bem como nas campanhas informativas de coleta seletiva. Posteriormente, foram trabalhados na Unidade Curricular de Educação Ambiental, os temas: conhecimento sobre meio ambiente e Educação Ambiental; conceitos, origem e problemas do lixo eletroeletrônico; práticas de Educação Ambiental relacionados ao lixo eletroeletrônico.

Para a confecção dos jogos educativos foram utilizados materiais eletrônicos descartados como fitas VHS, mouses, CDs, HDs, monitores, gabinetes, placas, entre outros. Por meio de linguagem simples e de abordagem direta, os jogos desenvolvidos foram projetados para que o estudante aprenda conceitos relevantes de cunho ambiental, de forma atrativa e dinâmica pelo simples ato de jogar. No quadro 1, verifica-se o nome do jogo, a imagem ilustrativa e os materiais utilizados para confecção.

Quadro 1: Descrição dos Jogos educativos confeccionados

\begin{tabular}{|c|c|c|c|}
\hline $\begin{array}{c}\text { Nome do } \\
\text { Jogo }\end{array}$ & Imagem Ilustrativa & $\begin{array}{l}\text { Materiais } \\
\text { Utilizados }\end{array}$ & Descrição/Dinâmica \\
\hline $\begin{array}{l}\text { Coleta } \\
\text { Radical }\end{array}$ & & $\begin{array}{l}\text { Cooler, HD, } \\
\text { memórias, } \\
\text { CDs, fonte, } \\
\text { gabinete, } \\
\text { controle de } \\
\text { videogame, } \\
\text { placas, teclas, } \\
\text { disquetes e } \\
\text { papel EVA. }\end{array}$ & $\begin{array}{l}\text { Jogo de tabuleiro, em que os } \\
\text { participantes são verdadeiros } \\
\text { defensores do meio ambiente que } \\
\text { precisam separar os resíduos por } \\
\text { tipo, em seus coletores. Durante } \\
\text { o jogo, eles receberão cartelas } \\
\text { que poderão ajudá-los ou } \\
\text { atrapalhá-los. Quem conseguir } \\
\text { completar seu coletor primeiro é o } \\
\text { vencedor. }\end{array}$ \\
\hline $\begin{array}{l}\text { Coleta } \\
\text { Maluca }\end{array}$ & & $\begin{array}{l}\text { Fitas VHS, } \\
\text { monitor } \\
\text { papel EVA. }\end{array}$ & $\begin{array}{l}\text { Jogo em ambiente aberto em que } \\
\text { os grupos precisam separar os } \\
\text { resíduos por tipo em seus } \\
\text { coletores. Durante o jogo, eles } \\
\text { terão que procurar cartelas e } \\
\text { resíduos que estarão espalhados } \\
\text { pelo ambiente e descartá-los nos } \\
\text { coletores corretos. A equipe que } \\
\text { coletar os resíduos no menor } \\
\text { tempo é a vencedora. }\end{array}$ \\
\hline
\end{tabular}

Continua... 


\begin{tabular}{|c|c|c|c|}
\hline $\begin{array}{c}\text { Nome do } \\
\text { Jogo }\end{array}$ & Imagem Ilustrativa & $\begin{array}{l}\text { Materiais } \\
\text { Utilizados }\end{array}$ & Descrição/Dinâmica \\
\hline $\begin{array}{l}\text { Memória } \\
\text { Seletiva }\end{array}$ & & $\begin{array}{l}\text { Fitas VHS e } \\
\text { papel EVA. }\end{array}$ & $\begin{array}{l}\text { Semelhante a um jogo de } \\
\text { memória, os participantes devem } \\
\text { formar pares entre os resíduos e } \\
\text { as correspondentes cores de } \\
\text { descarte. Vence aquele que } \\
\text { formar o maior número de pares. }\end{array}$ \\
\hline E-Bingo & & $\begin{array}{l}\text { Fitas VHS, } \\
\text { teclados e } \\
\text { disquetes. }\end{array}$ & $\begin{array}{l}\text { Cada jogador receberá uma } \\
\text { cartela, contendo as cores de } \\
\text { descarte, que deverá ser } \\
\text { preenchida, conforme os resíduos } \\
\text { vão sendo sorteados. Quem } \\
\text { conseguir completar a cartela } \\
\text { primeiro, é o vencedor. }\end{array}$ \\
\hline $\begin{array}{l}\text { Para\& } \\
\text { Separa }\end{array}$ & & $\begin{array}{l}\text { Disquetes, } \\
\text { fone de } \\
\text { ouvido } \\
\text { teclados. }\end{array}$ & $\begin{array}{l}\text { Jogo que consiste em preencher, } \\
\text { em grupo, uma tabela, na qual } \\
\text { cada coluna recebe a cor } \\
\text { correspondente a um tipo de } \\
\text { resíduo. Cada linha representa } \\
\text { uma rodada do jogo, sendo seu } \\
\text { término definido pelos jogadores. } \\
\text { O grupo deve preencher as } \\
\text { colunas com nomes de resíduos } \\
\text { que iniciam com a letra sorteada } \\
\text { em cada rodada. Vence quem } \\
\text { tiver o maior número de pontos. }\end{array}$ \\
\hline
\end{tabular}

Continua... 


\begin{tabular}{|c|c|c|c|}
\hline $\begin{array}{l}\text { Nome do } \\
\text { Jogo }\end{array}$ & Imagem Ilustrativa & $\begin{array}{l}\text { Materiais } \\
\text { Utilizados }\end{array}$ & Descrição/Dinâmica \\
\hline $\begin{array}{l}\text { CDescar- } \\
\text { tando }\end{array}$ & & $\begin{array}{l}\text { CDs e fitas } \\
\text { VHS. }\end{array}$ & $\begin{array}{l}\text { São distribuídos CDs para cada } \\
\text { jogador e vira-se o CD do topo do } \\
\text { baralho para ficar como o primeiro } \\
\text { no topo da pilha de descarte. } \\
\text { Cada jogador, na sua vez, pode } \\
\text { descartar um ou mais CDs, da } \\
\text { mesma cor, o resíduo } \\
\text { correspondente à cor de descarte } \\
\text { ou com o mesmo resíduo. } \\
\text { Existem CDs especiais (com } \\
\text { todas as cores, coringa). Quem } \\
\text { zerar a mão vence. }\end{array}$ \\
\hline $\begin{array}{c}\text { Falso e } \\
\text { Verdadeiro }\end{array}$ & & $\begin{array}{l}\text { Gabinete, } \\
\text { CDs, teclado } \\
\text { e pinos de } \\
\text { computador. }\end{array}$ & $\begin{array}{l}\text { Em cada rodada, o jogador deve } \\
\text { iniciar jogando o dado e andando } \\
\text { com seu peão o número de casas } \\
\text { indicadas. Ao final do seu } \\
\text { movimento, ele deve conferir em } \\
\text { qual casa caiu e cumprir o que o } \\
\text { ícone indica. Vai avançando ao } \\
\text { longo do tabuleiro, tentando } \\
\text { responder corretamente às } \\
\text { perguntas sobre o descarte de } \\
\text { lixo. Vence o primeiro jogador a } \\
\text { chegar na casa FIM. }\end{array}$ \\
\hline $\begin{array}{c}\text { Lixo } \\
\text { Enigmático }\end{array}$ & & $\begin{array}{l}\text { Imãs de HD, } \\
\text { fitas VHS e } \\
\text { papel EVA. }\end{array}$ & $\begin{array}{l}\text { Cada competidor deverá colocar } \\
\text { uma bandana na cabeça e } \\
\text { selecionar uma carta. Após, sem } \\
\text { olhar, encaixar a parte de metal } \\
\text { com imã da bandana. O jogador } \\
\text { da vez deve fazer três perguntas } \\
\text { a serem respondidas pelos } \\
\text { adversários, a fim de adivinhar } \\
\text { qual resíduo e qual a cor } \\
\text { correspondente ao descarte. Se } \\
\text { acertar ganha o jogo. }\end{array}$ \\
\hline $\begin{array}{l}\text { Dominó do } \\
\text { Descarte }\end{array}$ & & $\begin{array}{l}\text { Caixas de } \\
\text { fitas K7, fitas } \\
\text { VHS e papel } \\
\text { EVA. }\end{array}$ & $\begin{array}{l}\text { Distribuem-se sete caixas de fitas } \\
\text { para cada jogador e o iniciante } \\
\text { coloca uma na mesa. O próximo } \\
\text { deve encaixar, na sequência, o } \\
\text { tipo de resíduo com a cor de } \\
\text { descarte. Se o jogador não tiver a } \\
\text { peça correspondente, pode } \\
\text { comprar uma vez por rodada. } \\
\text { Vence o jogador que for o } \\
\text { primeiro a usar todas as suas } \\
\text { peças. }\end{array}$ \\
\hline
\end{tabular}

Fonte: Autoras, 2019.

Revbea, São Paulo, V. 15, № 5: 76-88, 2020. 
O objetivo principal dos jogos é ensinar, de forma lúdica, o descarte correto de cada tipo de resíduo, considerando as cores definidas pela Resolução no 275 (CONAMA, 2019). Destaca-se que no primeiro dia de aula, os estudantes respondem, anonimamente, a um desafio, no qual devem ligar o tipo de resíduo com a cor de descarte (Figura 1), a fim de obter-se um diagnóstico do conhecimento da turma acerca do assunto.

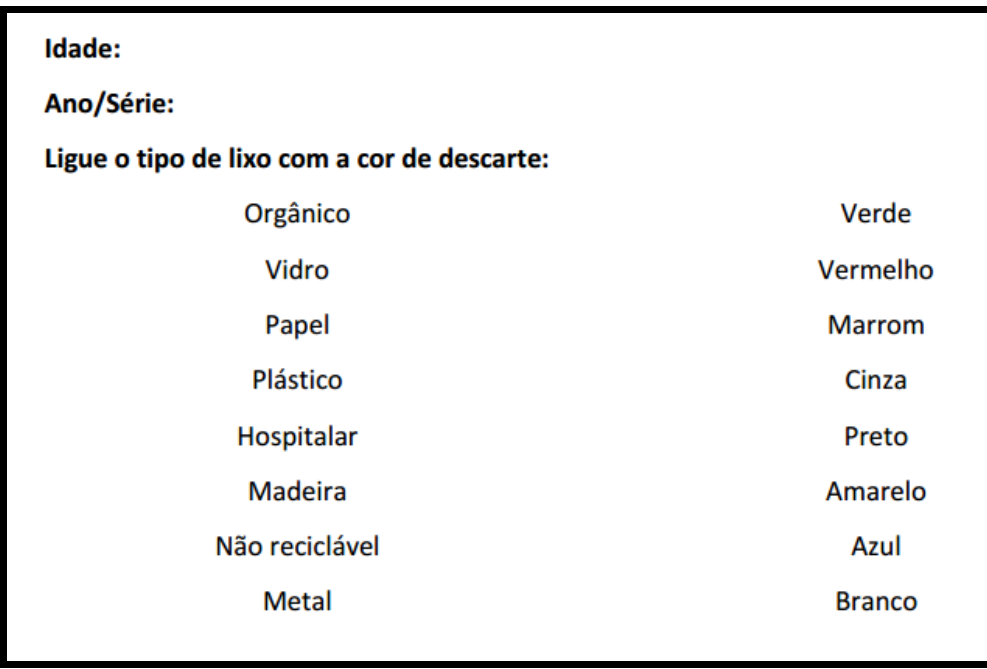

Figura 1: Desafio. Fonte: Autoras, 2019.

Com relação ao diagnóstico referente ao desafio da Figura 1, na turma 2019, a média de acertos dos estudantes foi de 2,67 e de erros 5,33. Três semanas depois, foram aplicados os jogos educativos de descarte de lixo eletroeletrônico, com a ajuda dos bolsistas do projeto de extensão E-Lixo. Os estudantes foram divididos em grupos, sendo os jogos aplicados simultaneamente. O professor atua como um mediador da ação.

Após o término de aplicação de cada jogo, foram empreendidas discussões sobre os temas relacionados ao meio ambiente e ao tipo de jogo, objetivando a reflexão e a elaboração de sugestões sobre problemas elencados na conversa. Para Miranda et al. (2007), a Educação Ambiental, por meio dos jogos educativos, permite ao estudante, a participação destes no diagnóstico dos problemas ambientais, bem como a busca por alternativas e soluções para os mesmos, estimulando à conscientização e a uma conduta ética no que concerne às questões ambientais. Loureiro (2007) afirma que os jogos educativos ao serem aplicados podem permitir a construção de um ponto de vista crítico acerca das ações e das posturas quanto à Educação Ambiental.

Após a experiência com os jogos em sala de aula, os estudantes da unidade curricular, juntamente com os bolsistas do projeto de extensão, aplicaram a mesma atividade com estudantes dos $6^{\circ}$ e $7^{\circ}$ anos do ensino fundamental, de uma escola estadual, localizada no distrito Luiz Englert, Sertão/RS. A Figura 2, retrata a aplicação dos jogos na escola. 


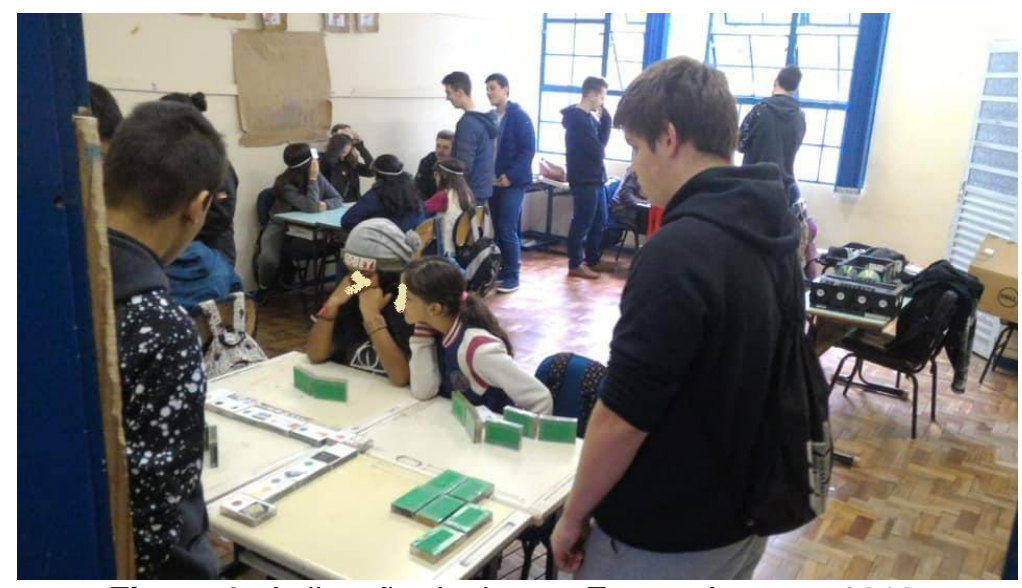

Figura 2: Aplicação de Jogos. Fonte: Autoras, 2019.

Os alunos puderam vivenciar a realidade de sala de aula de uma escola de ensino fundamental, pública e bastante carente, no papel de professores, tornando completa a sua experiência. No último dia de aula, os estudantes foram convidados a responder novamente o desafio (Figura 1) e realizarem uma avaliação dos jogos. Após a aplicação dos jogos, a média de acertos subiu para 3,88, aumentando em 45,34\% em relação a primeira aplicação, o que demonstra um resultado considerado positivo. É possível inferir que o uso sistemático dos jogos pode acarretar em melhoria no conhecimento dos estudantes sobre o descarte de lixo.

A fim de verificar a impressão dos estudantes acerca dos jogos, elaborou-se e aplicou-se um instrumento de avaliação (Figura 3), composto por sete questões objetivas e espaço para sugestões. O questionário foi distribuído de forma impressa e permitiu verificar os principais desafios e possibilidades em relação à aplicação de jogos educativos.

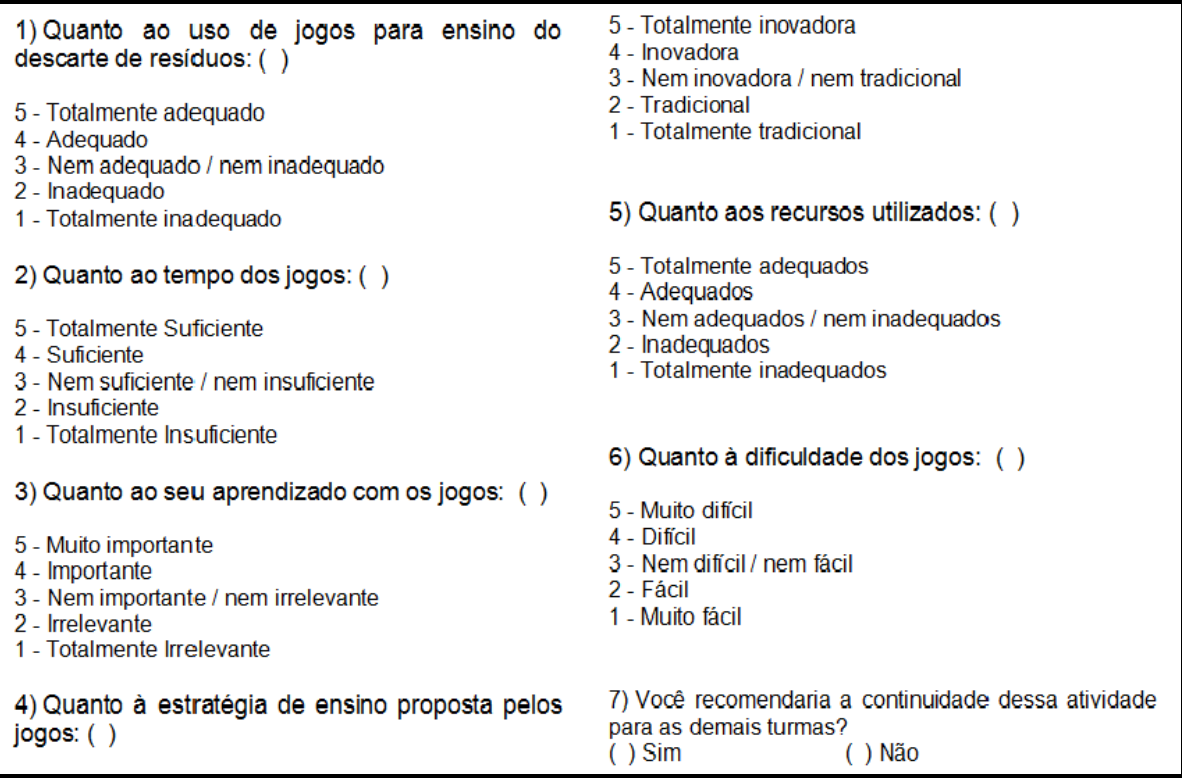

Figura 3: Instrumento de Avaliação. Fonte: Autoras, 2019. 
Investigou-se que quanto ao uso de jogos para o ensino do descarte de resíduos, $75 \%$ dos estudantes julgou como sendo totalmente adequado e $25 \%$ adequado. Com relação ao tempo para realização dos jogos, $50 \%$ considerou totalmente suficiente e $50 \%$ suficiente. Para $62,5 \%$ dos respondentes 0 aprendizado com jogos foi muito importante e para $37,5 \%$ foi importante. Quanto à estratégia de ensino proposta com os jogos, $62,5 \%$ avaliou como totalmente inovadora e $37,5 \%$ como inovadora. Acerca dos recursos utilizados nos jogos, $75 \%$ consideraram totalmente adequados e $25 \%$ adequados. Para $75 \%$ dos estudantes os jogos não foram nem difíceis, nem fáceis e $25 \%$ os considerou fáceis. Todos os respondentes foram favoráveis à continuidade das atividades com jogos para as próximas turmas. Com base na avaliação empreendida, a experiência foi positiva, permitindo atrelar teoria e prática, de forma lúdica. Os desafios remetem a desenvolver propostas ainda mais inovadoras e que possibilitem o processo de ensino e aprendizagem.

Afirma-se ainda, que alguns jogos são mais adequados para crianças a partir de cinco anos, como por exemplo, o Coleta Maluca, que é semelhante a uma caça ao tesouro, realizado em espaço aberto. Os demais jogos, podem ser jogados por pessoas de qualquer faixa etária.

\section{Considerações finais}

Considera-se relevante que o professor sempre busque incluir em sua prática pedagógica, novas alternativas de ensino, almejando atender aos diferentes estilos de aprendizagem dos estudantes. Os jogos educativos de descarte de lixo eletroeletrônico foram elaborados, aplicados e testados com êxito.

Averiguou-se que a finalidade educativa dos jogos foi cumprida, já que a partir dos mesmos, os estudantes puderam debater e construir conhecimentos acerca da área ambiental, além de fomentar o trabalho em equipe, a colaboração, a socialização, a criatividade, entre outros. Dito de outro modo, com os jogos educativos foi possível dar conta dos objetivos citados nos documentos reguladores e norteadores acerca da Educação Ambiental, tais como: reorientação do ensino para o desenvolvimento sustentável, aumento da consciência pública e promoção do treinamento.

Ainda, destaca-se que a parceria com o projeto de extensão E-Lixo teve um desfecho positivo, pois foram confeccionados jogos com materiais de baixo custo, em sua maioria, doados e que permitiram a mediação das aprendizagens. Os jogos educativos foram arquivados para utilização em outros semestres e se constituíram como um instrumento para reflexão sobre a Educação Ambiental.

\section{Agradecimentos}

Ao Instituto Federal de Educação, Ciência e Tecnologia do Rio Grande do Sul - Campus Sertão. 


\section{Referências}

ANASTASIOU, L.G.C.; PIMENTA, S.G. Docência no ensino superior. São Paulo: Cortez, 2002.

BRASIL. Lei no 9.394. De 20 de dezembro de 1996. Estabelece as diretrizes e bases da educação nacional. Disponível em: <http://www.planalto.gov.br/ccivil 03/leis/l9394.htm> Acesso em: 06 ago. 2019.

BRASIL. Lei no 9.795. De 27 de abril de 1999. Dispõe sobre a Educação Ambiental, institui a política nacional de Educação Ambiental e dá outras providências. Disponível em: $<$ http://www.planalto.gov.br/ccivil 03/leis/19795.htm>. Acesso em: 06 ago. 2019.

BRASIL. Decreto no 4.281. De 25 de junho de 2002, que regulamenta a Lei no 9.795, de 27 de abril de 1999, que institui a Política Nacional de Educação Ambiental, e dá outras providências. Disponível em: $<$ http://www.planalto.gov.br/ccivil 03/decreto/2002/d4281.htm> Acesso em: 06 ago. 2019.

BROUGÈRE, G. Jogo e educação. Porto Alegre: Artes Médicas, 1998.

CONAMA. Resolução CONAMA no 275. De 25 de abril de 2001. Publicada no DOU no 117-E, de 19 de junho de 2001, Seção 1, página 80 Estabelece 0 código de cores para os diferentes tipos de resíduos, a ser adotado na identificação de coletores e transportadores, bem como nas campanhas informativas para a coleta seletiva. Disponível em: $<$ http://www2.mma.gov.br/port/conama/legiabre.cfm?codlegi=273> Acesso em: 23 ago. 2019.

DE BORTOLI, L. Â. Projeto de Extensão 'E-lixo: ações de descarte, reutilização e Educação Ambiental'. Instituto Federal de Educação, Ciência e Tecnologia do Rio Grande do Sul - Campus Sertão, 2019. (Mimeo).

FIALHO, N.N. Os jogos pedagógicos como ferramentas de ensino. Disponível em: http://quimimoreira.net/Jogos\%20Pedagogicos.pdf Acesso em: 06 ago. 2019.

GOMES, R.R.; FRIEDRICH, M.A. Contribuição dos jogos didáticos na aprendizagem de conteúdos de Ciências e Biologia. In: EREBIO, 1, Anais. Rio de Janeiro, p. 389-392, 2001.

GRÜBEL, J.M.; BEZ, M.R. Jogos Educativos. Revista Renote - Novas Tecnologias na Educação, Porto Alegre, V. 4, N. 2, Dez., 2006.

IFRS Instituto Federal de Educação, Ciência e Tecnologia do Rio Grande do Sul - Campus Sertão. Projeto Pedagógico Do Curso Técnico Em Manutenção E Suporte Em Informática. Julho, 2013. (Mimeo).

LARA, I.C.M. Jogando com a Matemática de $5^{\mathbf{a}}$ a $8^{\mathbf{a}}$ série. São Paulo: Rêspel, 2004. 
LAYRARGUES, P.P. A resolução de problemas ambientais locais deve ser um tema gerador ou a atividade - fim da Educação Ambiental? In: REIGOTA, M. (org.). Verde Cotidiano: o meio ambiente em discussão. Rio de Janeiro: DP\&A Editora, 1999.

LOUREIRO, C.F.B. (Org.). A questão ambiental no pensamento crítico: natureza, trabalho e educação. Rio de Janeiro: Quartet, 2007.

MIRANDA, N.A. de et al. Educação Ambiental na Optica Discente: Análise de Um Pré-Teste. Disponível em: $<$ http://professores.aedb.br/seget/artigos06/713 Educacao\%20ambiental\%20n a\%20optica\%20discente-analise\%20pre-teste.pdf>. Acesso em: 12 ago. 2019.

OLIVEIRA, C.C.; COSTA, J.W.; MOREIRA, M. Ambientes Informatizados de Aprendizagem: Produção e Avaliação de Software Educativo. Campinas: Papirus, 2001.

ONU. Promoção de ensino, da conscientização e do treinamento. Agenda 21, 1992. Disponível em: <http://www.nepp-dh.ufri.br/onu13-3-36.html>. Acesso em: 10 set. 2019.

REIGOTA, M. Meio ambiente e representação social. São Paulo: Cortez, 1994.

SILVEIRA, R.S.; BARONE, D.A.C. Jogos Educativos computadorizados utilizando a abordagem de algoritmos genéticos. Anais do IV Congresso RIBIE, Brasília, $1998 . \quad$ Disponível em: <http://www.niee.ufrgs.br/eventos/R|B|E/1998/pdf/com pos dem/151.pdf> Acesso em: 12 ago. 2019.

TAYLOR, J. L. Guia sobre simulación y juegos para la educación ambiental. Santiago: OREAL/UNESCO, 1991.

TOZONI-REIS, M. F. C. Educação Ambiental: natureza, razão e história. 2a ed. Campinas: Autores Associados, 2008.

ZANON, D. A. V.; GUERREIRO, M.A.S.; OLIVEIRA; R.C. Jogo didático Ludo Químico para o ensino de nomenclatura dos compostos orgânicos: projeto, produção, aplicação e avaliação. Revista Ciências e Cognição, Rio de Janeiro, v. 13, n. 1, p. 72-81, 2008.

ZORZAL, E. R. et. al. Aplicação de Jogos Educacionais com Realidade Aumentada. Revista Renote - Novas Tecnologias na Educação, Porto Alegre, V. 6, N. 1, Julho, 2008. 